\title{
Qualidade da água da Lagoa do Josino, em Formiga (MG)
}

Joaquim Cordeiro Neto ${ }^{1}$

Michael Silveira Thebaldi²

Nathane Manuelle Silva Vilela ${ }^{3}$

Ascânio Vaz Silva ${ }^{4}$

Ivani Pose Martins 5

\section{Resumo}

A água é o recurso natural mais importante da Terra, sendo indispensável para a vida, assim, sua qualidade deve ser preservada. A partir disso, este trabalho tem por objetivo analisar a qualidade da água da Lagoa do Josino, localizada no município de Formiga (MG), a partir de análises físicas, químicas e microbiológicas. Para tal, foram coletadas amostras de água em diversos pontos da Lagoa do Josino, que apresenta diferentes formas de uso e ocupação em suas imediações. Foram analisados os seguintes parâmetros, entre os meses de agosto e outubro de 2015, pH, condutividade elétrica, temperatura, oxigênio dissolvido, turbidez, nitrato, nitrito, amônia, nitrogênio total, potássio, fósforo, ferro II, ferro III, demanda bioquímica de oxigênio (DBO), sólidos totais, sólidos dissolvidos totais, sólidos sedimentáveis, coliformes termotolerantes e totais, em cinco repetições. Os resultados obtidos para DBO, fósforo total, coliformes termotolerantes e totais não estão de acordo com o preconizado pela Resolução 357/2005 do CONAMA para Corpos Hídricos Classe 1 e pela Resolução 274/2000, do mesmo conselho.

Palavras-chave: Contaminação de águas superficiais. Balneabilidade. Gestão dos recursos hídricos.

\section{Introdução}

Os recursos hídricos são utilizados para distintas finalidades, entre as quais se destacam o abastecimento humano e animal, a geração de energia, a irrigação, a navegação, a aquicultura e a harmonia paisagística. Nas últimas décadas, a preocupação do ser humano com esse recurso cresceu muito, principalmente em função das ações indevidas e do uso irracional da água, que resulta em uma série de prejuízos à sociedade (SETTI et al., 2001).

Pelo fato de a qualidade da água ser fortemente influenciada pelo uso e manejo dos solos de uma bacia hidrográfica, o regime hídrico afeta o arraste de materiais superficiais no período chuvoso,

\footnotetext{
1 Viverde Consultoria Ambiental, graduado em Engenharia Ambiental e Sanitária. Formiga, Minas Gerais, Brasil. joaquim-neto90@hotmail.com. Rua Padre Eustáquio, 167, Nossa Senhora de Lourdes, Formiga (MG). CEP 35570-000.

2 Centro Universitário de Formiga, professor titular - doutor em Recursos Hídricos em Sistemas Agrícolas. Formiga, Minas Gerais, Brasil. msthebaldi@uniformg.edu.br. Avenida Doutor Arnaldo de Senna, 328, Água Vermelha, Formiga (MG). CEP 35570-000.

3 Universidade Federal de Viçosa, mestranda em Engenharia Civil. Viçosa, Minas Gerais, Brasil. nathanecivil@gmail.com. Avenida Peter Henry Rolfs, s/n, Campus universitário, Viçosa (MG). CEP 36570-900.

4 Centro Universitário de Formiga, graduando em Engenharia Ambiental e Sanitária. Formiga, Minas Gerais, Brasil. ascaniovazsilva@gmail.com. Avenida Doutor Arnaldo de Senna, 328, Água Vermelha, Formiga (MG). CEP 35570-000.

5 Centro Universitário de Formiga, professora titular - doutora em Ciência dos Alimentos. Formiga, Minas Gerais, Brasil. ivani@uniformg.edu.br. Avenida Doutor Arnaldo de Senna, 328, Água Vermelha - Formiga (MG). CEP 35570-000.
} 
bem como o aumento das concentrações de poluentes advindos de diversos despejos, devido à redução da vazão escoada no período de estiagem (LEMOS; FERREIRA NETO; DIAS, 2010).

De acordo com Damasceno (2005), em ambientes onde a ação antrópica é marcante, como nos centros urbanos, a qualidade da água deixa de ser afetada somente por fatores naturais. Assim, a situação dos recursos hídricos é agravada pelo crescimento acelerado e desordenado, sem a implementação adequada de saneamento básico.

Entre as principais causas do decréscimo da qualidade da água, encontra-se a eutrofização. Esse processo consiste em um aumento da fertilidade dos ambientes aquáticos, provocado pela entrada excessiva de nutrientes, principalmente fósforo e nitrogênio. Esses nutrientes são provenientes dos diferentes usos dos solos nas bacias hidrográficas e o aumento de sua concentração na água tem como consequência a perda da qualidade, especialmente pela promoção de florações expressivas de microalgas e macrófitas (XAVIER, 2005).

Como consequência da deterioração das águas, têm-se os altos índices de doenças de veiculação hídrica diretamente relacionadas à falta de saneamento. A água pode conter determinadas substâncias, elementos químicos e microrganismos, que devem ser eliminados ou reduzidos até concentrações que não sejam prejudiciais à saúde. Grande parte das doenças que se alastram nos países em desenvolvimento são provenientes do consumo de água com qualidade insatisfatória (BERNADO; PAZ, 2008).

Nesse contexto, lagoas associadas às áreas de alagamento dos rios são comuns no município de Formiga. São utilizadas extensivamente como áreas de lazer e moradia. 0 corpo hídrico popularmente conhecido como Lagoa do Josino pertence a um sistema hídrico anexo à Lagoa do Fundão, cuja área de abrangência foi bem maior no passado. Ambas estão separadas por um aterro onde está localizada uma via pública. As lagoas são alimentadas por um sistema de córregos anexos ao divisor de águas onde hoje se situam casas populares.

Assim, o objetivo deste trabalho foi caracterizar as condições atuais da qualidade da água utilizada para fins recreativos na Lagoa do Josino, Formiga (MG), em diversos pontos que apresentam diferentes formas de uso e ocupação de suas imediações, comparando a qualidade da água subsuperficial entre os pontos de amostragem com os padrões de qualidade preconizados pelas normas federais vigentes, de acordo com o preconizado pela Resolução 357/2005 do Conselho Nacional do Meio Ambiente (CONAMA) para Corpos Hídricos Classe 1 e pela Resolução 274/2000, do mesmo conselho.

\section{Material e métodos}

\section{Local do estudo}

O estudo foi desenvolvido na Lagoa do Josino, localizada no município de Formiga (MG). Encontra-se localizada na região sul da área urbana, a sudeste do Rio da Formiga. Foram coletadas amostras em seis pontos diferentes no período de estiagem, entre agosto e outubro de 2015, totalizando 5 repetições.

As localizações dos pontos de amostragem são apresentadas na Tabela 1. Essas localizações foram obtidas utilizando receptor GPS de navegação (modelo GPSMAP 62SC da Garmin). 0 datum de referência para localização é o WGS 84. 
Tabela 1. Localização dos pontos de coleta de água na Lagoa do Josino, em Formiga (MG)

\begin{tabular}{ccc}
\hline Ponto de coleta & Latitude & Longitude \\
\hline P1 & $454220,97 \mathrm{~m}$ & $7734255,94 \mathrm{~m}$ \\
\hline P2 & $454144,62 \mathrm{~m}$ & $7734235,90 \mathrm{~m}$ \\
\hline P3 & $454169,53 \mathrm{~m}$ & $7734173,65 \mathrm{~m}$ \\
\hline P4 & $454266,23 \mathrm{~m}$ & $7734110,56 \mathrm{~m}$ \\
\hline P5 & $454307,02 \mathrm{~m}$ & $7734071,53 \mathrm{~m}$ \\
\hline P6 & $454471,97 \mathrm{~m}$ & $7733860,16 \mathrm{~m}$ \\
\hline
\end{tabular}

Fonte: Elaborada pelos autores (2016).

Os pontos de coleta P1, P2 e P3 na Lagoa do Josino são apresentados na Figura 1.

Figura 1. Pontos de coleta P1 (A), P2 (B) e P3 (C) na Lagoa do Josino, em Formiga - MG.
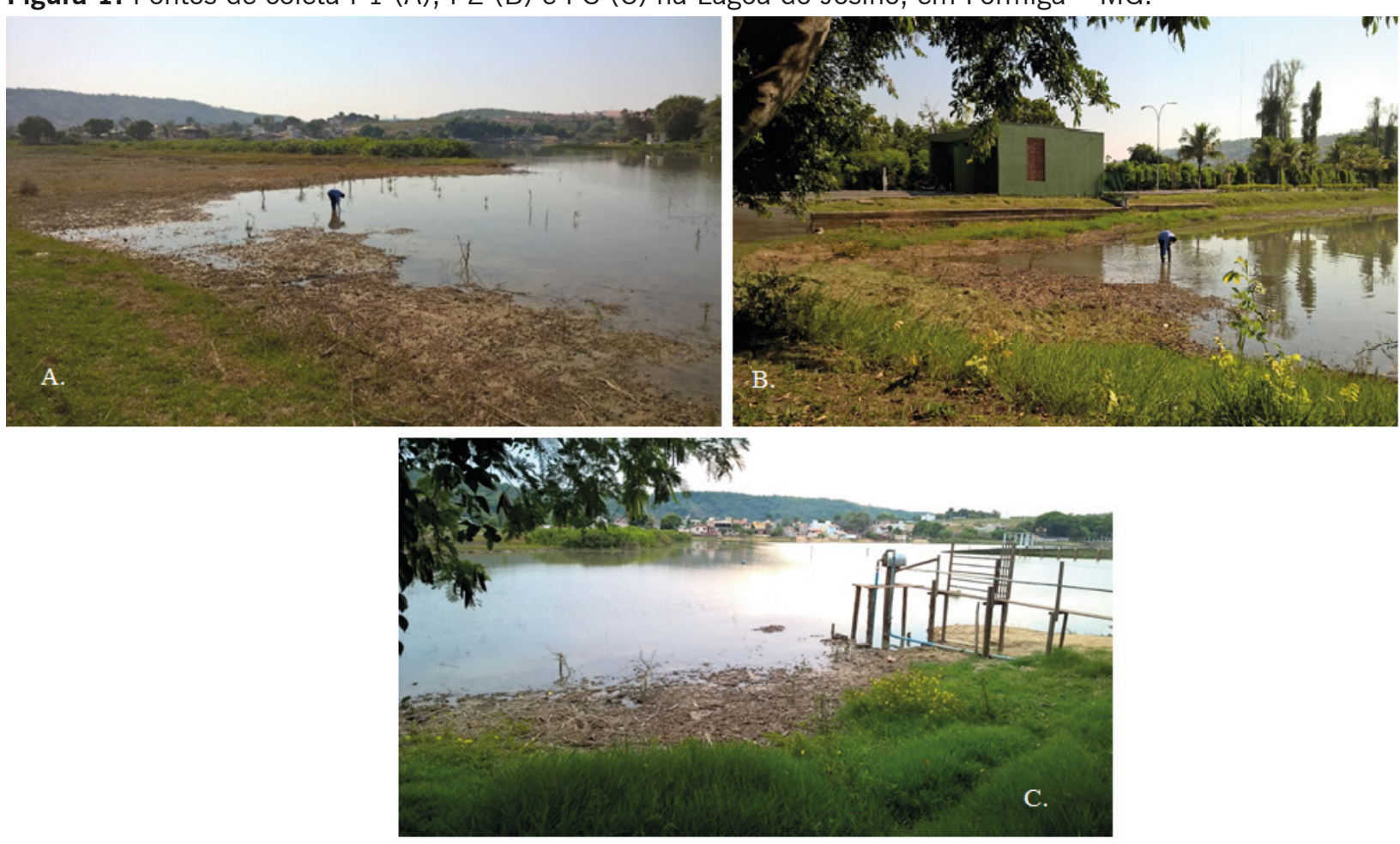

Fonte: Elaborada pelos autores (2016).

O ponto P1 (Figura 1A) é caracterizado por ser raso, pois é uma área da Lagoa que tem seu nível reduzido no período de estiagem. Ao seu lado, há um talude gramado que dá acesso a uma via asfaltada. O P2 (Figura 1B) está localizado no vértice Sudoeste da Lagoa, próximo a uma comporta que controla seu nível. Nessa área foram detectadas, em todas as coletas, presença de resíduos sólidos. P3, mostrado na Figura 1C, é caracterizado por haver uma estação de bombeamento de água para um clube recreativo, situado às margens da Lagoa. Os pontos de coleta P4, P5 e P6 na Lagoa do Josino são apresentados na Figura 2. 
Figura 2 - Pontos de coleta P4 (A), P5 (B) e P6 (C) na Lagoa do Josino, em Formiga (MG).
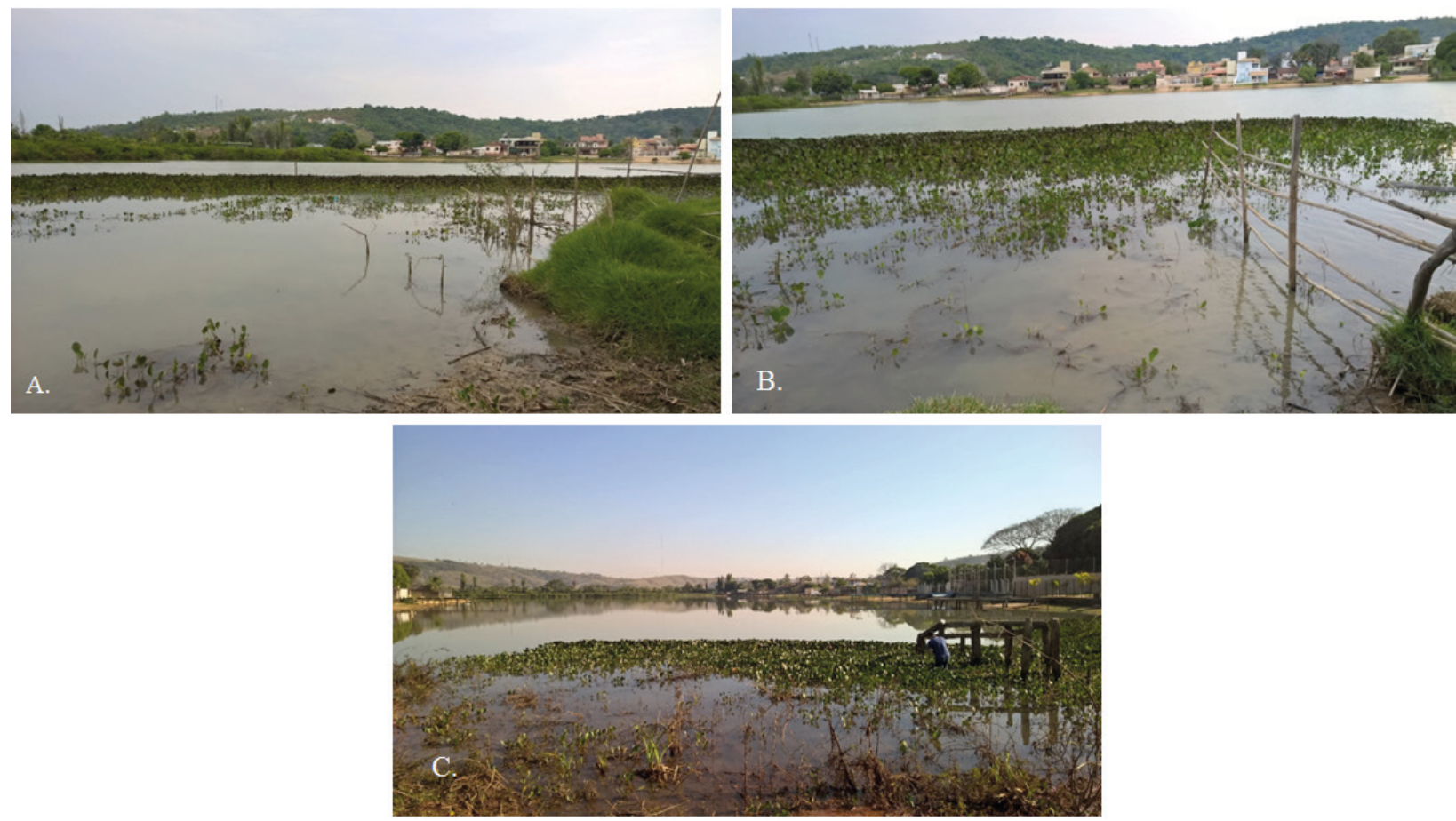

Fonte: Elaborada pelos autores (2016).

Uma particularidade comum a todos os pontos apresentados na Figura 2 é a presença de macrófitas, plantas indicativas de águas poluídas. Todos esses são localizados na margem sul da Lagoa, marcada pela ocupação de residências, que têm acesso direto às águas do corpo hídrico.

\section{Análises da água}

O oxigênio dissolvido foi determinado in loco. No ato da coleta das amostras de água, essas foram colocadas em recipiente térmico preenchido com gelo em gel, sendo o início dos procedimentos de determinação dos parâmetros de qualidade ocorrendo no máximo em meia hora após finalização da amostragem. No laboratório foram determinados os valores de $\mathrm{pH}$, condutividade elétrica, turbidez, nitrato, nitrito, amônia, nitrogênio total, potássio, fósforo, ferro II, ferro III, demanda bioquímica de oxigênio, sólidos totais, sólidos dissolvidos totais, sólidos sedimentáveis, coliformes termotolerantes e totais. Essas foram realizadas no Centro de Análises de Águas e Resíduos do Centro Universitário de Formiga.

O oxigênio dissolvido, com faixa de resolução de 0,01 até $20,0 \mathrm{mg} \mathrm{L}^{-1}$, foi obtido com oxímetro digital microprocessado AT-150 da Alfakit. $\mathrm{O}$ pH foi medido com um pHmetro digital microprocessado AT 315 da Alfakit, com compensação automática de temperatura e teclado a prova d'água. A faixa de leitura do aparelho era de 0,0 a 14,0, resolução de 0,01 e precisão de $\pm 1 \%$, enquanto que a condutividade elétrica foi adquirida com condutivímetro digital portátil com compensação automática de temperatura e escala de medição entre $0,00 \mathrm{mS} \mathrm{cm}^{-1}$ e $19,99 \mathrm{mS} \mathrm{cm}^{-1}$. A resolução do aparelho é de $0,01 \mathrm{mS} \mathrm{cm}^{-1}$, com precisão $\pm 2 \%$. A turbidez foi medida com turbidímetro digital com faixa de medição de 0 a 1000 NTU e resolução de 0,01 NTU e espectro de emissão de 880 nm.

A concentração de nitrito foi obtida seguindo o procedimento descrito por Fries e Getrost (1977), Método da Naftilamina. Os reagentes utilizados foram à base de Ácido Sulfanílico e à base de 1-Naftilamina. 
A concentração de nitrato foi obtida com o Método da Brucina (FRIES; GETROST, 1977). Os reagentes utilizados eram à base de veículo e indicador Brucina e à base de Ácido Sulfúrico.

Por outro lado, a concentração de amônia foi obtida utilizando o procedimento descrito por Merck (1972), Método de Nessler. Os reagentes utilizados eram Tartarato de Sódio e Potássio e solução básica contendo lodeto de Potássio e lodeto de Mercúrio.

Os valores de concentração de nitrogênio total foram adquiridos a partir da metodologia apresentada em American Public Health Association (APHA; AWWA; WEF, 1995), Método do Persulfato. Os reagentes utilizados eram à base de veículo e persulfato de potássio, hidróxido de sódio e sulfito. As amostras foram digeridas em aparelho apropriado, digital e microprocessado para digestão de até 9 amostras simultâneas, a $100^{\circ} \mathrm{C}$, por uma hora.

A concentração de potássio foi obtida pelo uso do procedimento descrito por Fries e Getrost (1977), Método do Tetrafenilborato de Sódio. Os reagentes utilizados eram à base de ácido cítrico, hidróxido de sódio e ácido clorídrico, tetrafenilborato de sódio em solução tampão com pH 8,0, enquanto as concentrações de fósforo total foram obtidas seguindo o procedimento descrito em APHA, AWWA e WEF (1995), Método Colorimétrico do Ácido Vanadomolibdicofosfórico. Os reagentes utilizados foram solução indicadora aquosa de fenolftaleína, ácido clorídrico 0,5 $\mathrm{N}$ e vanadato-molibdato.

Valores das concentrações de Fe II e Fe III foram obtidos seguindo o procedimento apresentado por Merck (1972), Método do Tiocianato. Os reagentes utilizados foram peróxido de hidrogênio, ácido clorídrico e tiocianato de potássio.

As concentrações de nitrato, nitrito, amônia, nitrogênio total, potássio, fósforo, ferro II e ferro III, em $\mathrm{mg} \mathrm{l}^{-1}$, foram obtidas em um fotocolorímetro de bancada com resolução de 0,001 $\mathrm{mg}^{-1}$ para concentração e de 0,01 para absorbância e precisão de 2 \%.

Os sólidos totais foram determinados pelo método gravimétrico, utilizando $30 \mathrm{~mL}$ de amostra. As amostras foram colocadas em cápsulas de porcelana e pesadas em balança com precisão de 0,01. Após secagem em estufa, as amostras foram esfriadas em dessecador e obtidos os pesos secos. Com a diferença de pesos em razão do volume de amostra, foram obtidas as concentrações de sólidos totais, enquanto os Sólidos Sedimentáveis foram determinados utilizando um cone Inhoff e os Sólidos Dissolvidos Totais determinados pela relação citada por Paganini (1997), em que SDT $\left(\mathrm{mg} \mathrm{l}^{-1}\right)=\mathrm{CE}$ $\left(\mathrm{dS} \mathrm{m} \mathrm{m}^{-1}\right) \times 640$.

$\mathrm{A} \mathrm{DBO}_{5}$ foi determinada pelo método de titulação iodométrica, seguindo o Standard methods for examination of water and wastewater (APHA; AWWA; WEF, 1995), sendo as amostras incubadas a $20{ }^{\circ} \mathrm{C}$. Os reagentes utilizados para preparar a água de diluição foram: fosfato de potássio, sódio, cloreto de amônio, sulfato de magnésio, cloreto de cálcio e cloreto férrico. A determinação do oxigênio dissolvido na água foi feita com a utilização de oxímetro.

Para obtenção das unidades formadoras de colônia de coliformes fecais e totais, por $100 \mathrm{ml}$ de água, foram utilizados kits Colipaper, da Alfakit, encubados em estufa microbiológica por 15 horas. As amostras foram coletadas em frascos plásticos autoclaváveis de $250 \mathrm{ml}$. Antes da coleta, os frascos foram passados por autoclave vertical, para esterilização.

\section{Análises dos resultados}

Os resultados obtidos pelas análises foram comparados aos padrões de qualidade descritos nas Resoluções 274/2000 (BRASIL, 2000) e 357/2005 (BRASIL, 2005) do CONAMA. As concentrações dos parâmetros de qualidade da água para cada ponto estudado foram comparadas pelo teste $\mathrm{F}$ a 5 \% 
de significância. Nas análises em que o teste de F foi significativo, realizou-se o teste de Scott-Knott, também com $5 \%$ de probabilidade para comparação de médias.

\section{Resultados e discussão}

A análise de variância e resultados dos testes de comparação de médias para os parâmetros oxigênio dissolvido, demanda bioquímica de oxigênio, ferro II, ferro III, coliformes fecais e coliformes totais nos diferentes pontos de análise são mostrados na Tabela 2.

Tabela 2. Análise de Variância e resultados dos testes de comparação de médias para os parâmetros oxigênio dissolvido, demanda bioquímica de oxigênio, ferro II, ferro III, coliformes fecais e coliformes totais nos diferentes pontos de análise.

\begin{tabular}{|c|c|c|c|c|c|c|c|c|}
\hline \multirow{2}{*}{ Parâmetro } & \multicolumn{6}{|c|}{ Pontos de Análise } & \multirow[t]{2}{*}{ QM } & \multirow[t]{2}{*}{ cv (\%) } \\
\hline & P1 & P2 & P3 & P4 & P5 & P6 & & \\
\hline DBO & 167,07 a & $175,40 \mathrm{a}$ & 178,65 a & $152,72 \mathrm{a}$ & $173,39 a$ & 164,48 a & $441,7641^{\text {ns }}$ & 42,85 \\
\hline OD & $6,08 \mathrm{a}$ & $5,64 a$ & 6,13 a & 5,48 a & 5,73 a & 5,26 a & $0,5710^{\mathrm{ns}}$ & 18,96 \\
\hline $\mathrm{Fe}^{2+}$ & $0,05 b$ & $0,25 a$ & $0,09 \mathrm{~b}$ & $0,09 \mathrm{~b}$ & $0,07 \mathrm{~b}$ & $0,09 \mathrm{~b}$ & $0,0257^{* *}$ & 73,93 \\
\hline $\mathrm{Fe}^{3+}$ & $0,272 \mathrm{a}$ & $1,198 \mathrm{a}$ & $0,370 \mathrm{a}$ & $0,388 \mathrm{a}$ & $0,290 \mathrm{a}$ & 0,352 a & $0,6318^{\mathrm{ns}}$ & 130,82 \\
\hline CF & 6890 a & 6773 a & 3856 a & 5643 a & 7547 a & 3920 a & $12521192^{\text {ns }}$ & 84,17 \\
\hline CT & 15637 a & 13206 a & 13323 a & 11269 a & 13520 a & $11173 \mathrm{a}$ & $13701475^{\mathrm{ns}}$ & 69,40 \\
\hline
\end{tabular}

Em que: DBO: Demanda bioquímica de oxigênio $\left(\mathrm{mg} \mathrm{l}^{-1}\right)$, OD: oxigênio dissolvido $\left(\mathrm{mg} \mathrm{l}^{-1}\right)$, $\mathrm{Fe}^{2+}$ : Ferro II (mg $\mathrm{l}^{-1}$ ), $\mathrm{Fe}^{3+}$ : Ferro III ( $\mathrm{mg} \mathrm{l}^{-1}$ ), CF: coliformes termotolerantes (UFC $100 \mathrm{ml}^{-1}$ ), CT: coliformes totais (UFC $100 \mathrm{ml}^{-1}$ ), QM: quadrado médio, cv: coeficiente de variação, ns: não significativo, *: significativo ao teste de $\mathrm{F}$ a $5 \%$ de probabilidade. Valores na horizontal seguidos por mesma letra maiúscula não diferem estatisticamente ao teste de Scott-Knott a $5 \%$ de probabilidade.

Fonte: Elaborada pelos autores (2016).

Analisando a Tabela 2, tem-se que as médias das concentrações de DBO em todos os pontos avaliados foram iguais, estando todos os valores fora do padrão estabelecido por Brasil (2005), para corpos hídricos classe 1 , que é $3 \mathrm{mg} \mathrm{l}^{-1}$. As altas concentrações de DBO obtidas neste estudo estão ligadas diretamente à ocupação das margens da Lagoa do Josino, uma vez que se tem a informação de que há aporte de esgoto doméstico em suas águas.

Franco e Hernandez (2012) registraram diferença significativa em seus estudos para os valores de DBO entre os períodos seco e chuvoso, constatando valores mais elevados de DBO no período seco. Assim, pode ocorrer melhora da qualidade da água da Lagoa do Josino durante e logo após o período chuvoso, devido à diluição da matéria orgânica.

Jerônimo e Souza (2013), ao estudarem a qualidade da água da Lagoa de Extremoz (RN), correlacionaram-na a índices pluviométricos, concluindo que a influência dos índices pluviométricos na água da Lagoa de Extremoz tem uma maior tendência na solubilização de íons e nos aspectos organolépticos, não tendo praticamente nenhum efeito no pH e nos níveis de matéria orgânica presentes.

Assim como o ocorrido para DBO, não houve diferenças significativas entre as concentrações de OD obtidas nos diversos pontos estudados. Dentre essas, os valores obtidos em P2, P4, P5 e P6 não estiveram de acordo com o padrão exigido pela Resolução n 357/2005 do CONAMA (BRASIL, 2005), ou seja, acima de $6 \mathrm{mg} \mathrm{L}^{-1}$, para corpos hídricos Classe 1 . Em todas as amostragens realizadas, foi de- 
tectada a presença de resíduos sólidos e manchas de óleo em P2 e P4, além de plantas aquáticas em alto grau de desenvolvimento em P4, P5 e P6. A não ocorrência de diferenças significativas de DBO e OD nos diversos pontos analisados na lagoa mostra tendência à poluição generalizada nessa.

O oxigênio dissolvido é de essencial importância para os organismos aeróbios, além de ser o principal parâmetro de caracterização dos efeitos da poluição das águas por despejos orgânicos e, durante a estabilização da matéria orgânica, as bactérias fazem uso do oxigênio em seus processos respiratórios, podendo vir a causar uma redução de sua concentração no meio (VON SPERLING, 2005). Os valores obtidos comparados ao valor médio de oxigênio dissolvido de saturação, calculado para a região de estudo (aproximadamente $8,3 \mathrm{mg} \mathrm{L}^{-1}$, considerando $20{ }^{\circ} \mathrm{C}$ de temperatura da água e 785 m de altitude do município), indicam a presença de matéria orgânica na água, fato que pode ser evidenciado pelas concentrações de demanda bioquímica de oxigênio (DBO) obtidas.

Longo Júnior, Manzione e Ferreira (2011) investigaram a qualidade da água na Lagoa do Córrego Furninha, localizada no município de Ourinhos (SP) e a jusante do lixão municipal, obtendo, em média, uma concentração de OD de $6,67 \mathrm{mg} \mathrm{L}^{-1}$, maior que as concentrações de OD verificadas neste estudo, o que evidencia a qualidade inferior das águas da Lagoa do Josino.

Brasil (2005) estabelece como valor máximo permitido de ferro dissolvido em corpos hídricos classe 1 a concentração de 0,3 $\mathrm{mg} \mathrm{L}^{-1}$. Na ausência de oxigênio dissolvido, como em lençóis subterrâneos, fundo de lagos e represas ou efluentes residuais, o ferro se apresenta na forma solúvel (Ferro II). Caso a água contendo as formas reduzidas seja exposta ao ar atmosférico, esse volta a se oxidar em sua forma insolúvel (Ferro III), que pode causar cor alaranjada na água (VON SPERLING, 2005). Portanto, a resolução $n^{\circ} 357 / 2005$ (BRASIL, 2005) refere-se à concentração presente de $\mathrm{Fe}^{2+}$ para avaliação da qualidade de água.

Em média, todos os pontos avaliados apresentaram concentração de Ferro II dentro do limite estabelecido em Brasil (2005), tendo sido obtida em P2 a concentração de 0,25 mg L-1. Porém, vê-se pela análise da Tabela 2 que estatisticamente as concentrações de $\mathrm{Fe}^{2+}$ foram iguais em todos os pontos avaliados, assim como ocorrido para as concentrações de $\mathrm{Fe}^{3+}$.

As águas da Lagoa do Josino podem ser consideradas impróprias para o contato humano, uma vez que em média em todos os pontos foi obtida quantidade de coliformes fecais superiores a 2500 UFC/100 ml. Tanto para coliformes termotolerantes quanto para totais, os valores obtidos nos diversos pontos de amostragem não diferiram estatisticamente a $5 \%$ de probabilidade pelo Teste $\mathrm{F}$ (Tabela 2).

Lemos, Ferreira Neto e Dias (2010), ao estudarem a qualidade da água de uma Lagoa no município de Mossoró (RN) em quatro pontos selecionados próximos à área de influência da bacia urbanizada da Lagoa, observaram que a variação na qualidade bacteriológica da água comprometeu a balneabilidade da Lagoa, em particular logo após o período das chuvas. Se a mesma tendência ocorrer na Lagoa do Josino, que está localizada em área urbanizada, devido ao escoamento superficial ocorrido no período chuvoso, sua situação quanto à presença de coliformes piorará, como apresentado por Tucci (2015), que cita que a qualidade de águas pluviais não é melhor que a de efluentes de tratamento secundário, sendo a quantidade de material suspenso na água de drenagem pluvial superior à encontrada em esgoto in natura, e, quanto mais urbanizada a bacia hidrográfica, maior a produção de sedimentos.

A análise de variância e resultados dos testes de comparação de médias para os parâmetros condutividade elétrica, turbidez, $\mathrm{pH}$, sólidos dissolvidos totais, sólidos sedimentáveis e sólidos totais nos diferentes pontos de análise estão apresentados na Tabela 3. 
Tabela 3. Análise de Variância e resultados dos testes de comparação de médias para os parâmetros condutividade elétrica, turbidez, $\mathrm{pH}$, sólidos dissolvidos totais, sólidos sedimentáveis e sólidos totais nos diferentes pontos de análise.

\begin{tabular}{|c|c|c|c|c|c|c|c|c|}
\hline \multirow{2}{*}{ Parâmetro } & \multicolumn{6}{|c|}{ Pontos de Análise } & \multirow[t]{2}{*}{ QM } & \multirow[t]{2}{*}{ cv (\%) } \\
\hline & P1 & P2 & P3 & P4 & P5 & P6 & & \\
\hline CE & $0,116 a$ & $0,118 \mathrm{a}$ & $0,116 a$ & $0,112 \mathrm{a}$ & $0,118 a$ & $0,124 a$ & $0,00008^{\text {ns }}$ & 17,57 \\
\hline Turbidez & $0,00 \mathrm{a}$ & $0,13 a$ & $14,73 \mathrm{~b}$ & $2,52 \mathrm{a}$ & $1,92 \mathrm{a}$ & $0,00 \mathrm{a}$ & $164,97^{\mathrm{ns}}$ & 272,21 \\
\hline $\mathrm{pH}$ & 7,638 a & $7,684 a$ & 7,896 a & 7,906 a & 7,750 a & $7,974 a$ & $0,0925^{\mathrm{ns}}$ & 4,82 \\
\hline SDT & $74,24 \mathrm{a}$ & 75,52 a & $74,24 \mathrm{a}$ & 71,68 a & 75,52 a & 79,36 a & $31,6757^{\mathrm{ns}}$ & 17,57 \\
\hline SS & $0,20 a$ & $0,22 a$ & $0,32 \mathrm{a}$ & $0,42 a$ & $0,00 \mathrm{a}$ & $0,00 \mathrm{a}$ & $0,1429^{\text {ns }}$ & 247,25 \\
\hline ST & $173 \mathrm{a}$ & $200 \mathrm{a}$ & 185 a & $210 \mathrm{a}$ & $256 a$ & $284 \mathrm{a}$ & $9435,3133^{\text {ns }}$ & 57,72 \\
\hline
\end{tabular}

Em que: CE: condutividade elétrica $\left(\mathrm{dS} \mathrm{m}^{-1}\right)$, Turbidez (UNT), SDT: sólidos dissolvidos totais ( $\mathrm{mg} \mathrm{L}^{-1}$ ), SS: sólidos sedimentáveis ( $\left.\mathrm{ml} \mathrm{L}^{-1}\right)$, ST: sólidos totais $\left(\mathrm{mg} \mathrm{L}^{-1}\right), \mathrm{QM}$ : quadrado médio, cv: coeficiente de variação, ns: não significativo, *: significativo ao teste de $\mathrm{F}$ a $5 \%$ de probabilidade. Valores na horizontal seguidos por mesma letra maiúscula não diferem estatisticamente ao teste de Scott-Knott a $5 \%$ de probabilidade.

Fonte: Elaborada pelos autores (2016).

$\mathrm{Na}$ Tabela 3, tem-se que os valores médios de condutividade elétrica foram iguais em todos os pontos avaliados da Lagoa do Josino, o que infere que há a mesma concentração de sais em todos os pontos analisados. Como a CE da água está relacionada à presença de íons dissolvidos, provenientes de qualquer fonte, natural (como da dissociação de sais do solo e seu transporte ao corpo hídrico) ou não (devido à ação antrópica), não se pode afirmar a origem desses sais. Desta forma, não há padrão deste parâmetro preconizado em Brasil (2005).

Diferentemente dos parâmetros avaliados até agora, foram identificadas diferenças significativas para valores de turbidez entre os pontos amostrais, sendo o maior valor médio encontrado em P3, 14,73 UNT. Os resultados encontrados em P3 se devem ao fato deste ponto ser localizado próximo a uma unidade de bombeamento, que confere agitação em materiais particulados de solo que se encontram no fundo da Lagoa. Esses valores foram obtidos em época de rebaixamento do nível de água do corpo hídrico. Há também de se salientar que as médias zero obtidas em P1 e P6 podem ser devido ao limite de detecção do turbidímetro utilizado.

Analisando as médias para cada ponto de amostragem, todos os valores de turbidez estiveram dentro do padrão exigidos pela resolução do CONAMA 357/2005, que é de até 40 UNT para corpos hídricos Classe 1 (Tabela 3). Normalmente, por serem ambientes lênticos, há tendência de sedimentação dos materiais sólidos em lagoas, o que contribui para a baixa turbidez encontrada.

Para $\mathrm{pH}$, todas as médias dos valores encontrados estiveram dentro da faixa considerada neutra em Brasil (2005), que vai de 6 a 9, como pode ser visualizado na Tabela 3. Além disso, todas as médias encontradas nos diferentes pontos da Lagoa do Josino foram iguais estatisticamente a $5 \%$ de probabilidade pelo teste $\mathrm{F}$.

Quanto à avaliação dos sólidos dissolvidos totais, esses são diretamente relacionados à condutividade elétrica da água. Pela análise da Tabela 3, não foram identificadas diferenças significativas entre as concentrações médias avaliadas nos pontos amostrais. Analisando as médias para cada ponto de amostragem, os valores estiveram dentro do padrão exigido pela Resolução n 357/2005 do CONAMA (BRASIL, 2005), que para corpos hídricos Classe 1, não devem ultrapassar 500 mg l- ${ }^{1}$.

Comparando, em Lagoa a jusante do lixão de Ourinhos (SP), Longo Júnior, Manzione e Ferreira (2011) obtiveram, em média, um valor de 0,60 dS m-1 de CE, maior que o obtido neste estudo e que geraria uma concentração de sólidos dissolvidos totais de $384 \mathrm{mg} \mathrm{L}^{-1}$. 
Brasil (2005) não estabelece padrão de sólidos sedimentáveis para corpos hídricos classe 1; além disso, todos os valores obtidos para este parâmetro de qualidade da água foram iguais estatisticamente entre os pontos de amostragem estudados (Tabela 3). A quantidade de sólidos presentes em pontos específicos dos corpos d'água é bastante influenciada pelas condições físicas do local, como proteção vegetal da margem e juntamente com a velocidade de escoamento da água unida à altura da lâmina d'água. Porém, em ambientes lênticos tende a ocorrer a decantação desses, por isso não se observaram grandes quantidades de sólidos sedimentáveis.

Para sólidos totais, Brasil (2005) preconiza que, em corpos hídricos Classe 1, materiais flutuantes e resíduos sólidos objetáveis, inclusive espumas não naturais, devem estar ausentes, o que não foi observado nos pontos de amostragem. Em se tratando da comparação entre os valores obtidos em cada um dos pontos de amostragem, não foi detectada diferença significativa a $5 \%$ de probabilidade estatística, pelo teste $\mathrm{F}$.

Na Tabela 4, são apresentados a análise de variância e os resultados dos testes de comparação de médias para os parâmetros nitrogênio total, amônia, nitrito, nitrato, fósforo e potássio, nos diferentes pontos de análise.

Tabela 4. Análise de Variância e resultados dos testes de comparação de médias para os parâmetros nitrogênio total, amônia, nitrito, nitrato, fósforo e potássio nos diferentes pontos de análise.

\begin{tabular}{ccccccccc}
\hline \multirow{2}{*}{ Parâmetro Pontos de Análise } & & QM & cv (\%) \\
\cline { 2 - 8 } & P1 & P2 & P3 & P4 & P5 & P6 & & \\
\hline $\mathrm{N}_{\text {Total }}$ & $1,43 \mathrm{a}$ & $2,38 \mathrm{a}$ & $1,54 \mathrm{a}$ & $1,49 \mathrm{a}$ & $1,88 \mathrm{a}$ & $1,62 \mathrm{a}$ & $0,6435^{\text {ns }}$ & 50,56 \\
$\mathrm{NH}^{3+}$ & $0,03 \mathrm{a}$ & $0,03 \mathrm{a}$ & $0,05 \mathrm{a}$ & $0,04 \mathrm{a}$ & $0,04 \mathrm{a}$ & $0,03 \mathrm{a}$ & $0,0003^{\text {ns }}$ & 141,19 \\
$\mathrm{NO}_{2}$ & $0,03 \mathrm{a}$ & $0,04 \mathrm{a}$ & $0,09 \mathrm{a}$ & $0,03 \mathrm{a}$ & $0,02 \mathrm{a}$ & $0,01 \mathrm{a}$ & $0,0038^{\text {ns }}$ & 149,73 \\
$\mathrm{NO}_{3}$ & $0,65 \mathrm{a}$ & $0,78 \mathrm{a}$ & $0,67 \mathrm{a}$ & $0,54 \mathrm{a}$ & $0,62 \mathrm{a}$ & $0,61 \mathrm{a}$ & $0,0316^{\text {ns }}$ & 103,48 \\
$\mathrm{P}$ & $1,242 \mathrm{a}$ & $2,016 \mathrm{a}$ & $1,416 \mathrm{a}$ & $1,686 \mathrm{a}$ & $1,410 \mathrm{a}$ & $1,362 \mathrm{a}$ & $0,3987^{\text {ns }}$ & 60,68 \\
$\mathrm{~K}$ & $7,500 \mathrm{a}$ & $7,920 \mathrm{a}$ & $6,900 \mathrm{a}$ & $4,986 \mathrm{a}$ & $4,614 \mathrm{a}$ & $4,322 \mathrm{a}$ & $12,5015^{\text {ns }}$ & 84,08 \\
\hline
\end{tabular}

Em que: $\mathrm{N}_{\text {Total }}$ : nitrogênio total $\left(\mathrm{mg} \mathrm{L}^{-1}\right), \mathrm{NH}^{3+}$ : amônia $\left(\mathrm{mg} \mathrm{L}^{-1}\right), \mathrm{NO}_{2}$ : nitrito $\left(\mathrm{mg} \mathrm{L}^{-1}\right), \mathrm{NO}_{3}$ : nitrato $\left(\mathrm{mg} \mathrm{L}^{-1}\right)$, P: fósforo ( $\left.\mathrm{mg} \mathrm{L}^{-1}\right), \mathrm{K}$ : potássio ( $\mathrm{mg} \mathrm{l}^{-1}$ ), QM: quadrado médio, $\mathrm{cv}$ : coeficiente de variação, ns: não significativo, *: significativo ao teste de $\mathrm{F}$ a $5 \%$ de probabilidade. Valores na horizontal seguidos por mesma letra maiúscula não diferem estatisticamente ao teste de Scott-Knott a $5 \%$ de probabilidade.

Fonte: Elaborada pelos autores (2016).

Em função de processos bioquímicos de oxidação, o nitrogênio se alterna entre várias formas, sendo que no meio aquático pode ser encontrado nas formas molecular, nitrogênio orgânico, amônia livre, íon amônio, íon nitrito e íon nitrato (VON SPERLING, 2005).

Assim, as concentrações de nitrogênio total na água da Lagoa do Josino nos diversos pontos avaliados e amostragens são mostradas na Tabela 4. Nessa, tem-se que não foram obtidas diferenças significativas na concentração deste parâmetro entre os pontos amostrados na Lagoa do Josino. Quanto à adequação à legislação, Brasil (2005) não dispõe de concentração máxima estabelecida para esse parâmetro.

Para o parâmetro de qualidade da água amônia, Brasil (2005) estabelece como padrão de qualidade de corpos hídricos classe 1 concentração máxima de $2 \mathrm{mg} \mathrm{L}^{-1}$ de nitrogênio amoniacal em faixa de $\mathrm{pH}$ entre 7,5 e 8,0 e 1,0 $\mathrm{mg} \mathrm{L}^{-1}$ para $\mathrm{pH}$ entre 8,0 e 8,5, condições presentes nos pontos avaliados. Além disso, as médias das concentrações obtidas nos pontos de coleta foram estatisticamente iguais. No processo de nitrificação em corpos d'água, a amônia é oxidada a nitrito e este a nitrato. $A$ amônia em sua forma livre é diretamente tóxica aos peixes (VON SPERLING, 2005). 
Avaliando-se a média dos resultados obtidos de nitrito (Tabela 4), a concentração desse foi estatisticamente igual a $5 \%$ de probabilidade pelo teste $\mathrm{F}$ em todos os pontos; para a qualidade de corpos hídricos classe 1 , todos os pontos atenderam à legislação (concentração máxima permitida de 1,0 $\mathrm{mg} \mathrm{L}^{-1}$ ).

Brasil (2005) apresenta que esse parâmetro deve possuir concentração máxima de $10,0 \mathrm{mg} \mathrm{L}^{-1} \mathrm{em}$ corpos hídricos classe 1, padrão atendido em todos os pontos. Adicionalmente, a análise de variância para nitrato não mostrou diferenças significativas (teste $\mathrm{F}$ a $5 \%$ de probabilidade), não havendo, portanto, diferença entre os valores obtidos nos diversos pontos da Lagoa do Josino (Tabela 4).

0 fósforo bem como os compostos nitrogenados são nutrientes essenciais para o crescimento dos microrganismos responsáveis pela estabilização da matéria orgânica (VON SPERLING, 2005), sendo então parâmetros de importante controle em ambientes lênticos, como lagoas, no que se refere à susceptibilidade à eutrofização.

Diante disso, as médias das concentrações de fósforo em cada um dos pontos amostrais na Lagoa do Josino são apresentadas na Tabela 4. Pelo teste F a 5 \% de probabilidade estatística, todas as médias de concentração de fósforo foram iguais, porém, esses estiveram fora dos padrões exigidos pela Resolução n ${ }^{0}$ 357/2005 do CONAMA, que estabelece 0,025 mg L-1 para corpos hídricos classe 1, caracterizados como ambientes lênticos. Esse fato corrobora as observações de desenvolvimento de plantas aquáticas na Lagoa do Josino, o que infere possível trofia do corpo d'água.

Em estudo na Lagoa do Taí, no município de São João da Barra (RJ), Viana et al. (2013) observaram concentrações de fósforo variando de 0,01 $\mathrm{mg} \mathrm{L}^{-1}$ a 0,1 $\mathrm{mg} \mathrm{L}^{-1}$, com média de 0,04 $\mathrm{mg} \mathrm{L}^{-1}$.

Os autores supracitados destacam em seu estudoque um total de 31 amostras apresentaram resultados acima do valor máximo permitido para ambientes lênticos $\left(0,03 \mathrm{mg} \mathrm{L}^{-1}\right)$ em águas doces de classe 2 por Brasil (2005), sendo esse fato um dos possíveis responsáveis pela eutrofização observada nas margens e em uma área de aproximadamente $1,5 \mathrm{~km}$ que divide a lagoa em duas partes ou seções. Essa comparação mostra a avançada eutrofização na Lagoa do Josino, uma vez que a concentração média mínima observada de fósforo neste estudo foi $1,242 \mathrm{mg} \mathrm{L}^{-1}$.

Pela análise da Tabela 4, tem-se que as concentrações de potássio obtidas nos pontos amostrais foram estatisticamente iguais pelo teste $\mathrm{F}$ a $5 \%$ de probabilidade estatística, sendo o limite inferior de concentração obtido 4,322 $\mathrm{mg} \mathrm{L}^{-1}$. A concentração de potássio em corpos hídricos classe 1 não é padronizada pela Resolução n 357/2005 do CONAMA (BRASIL, 2005), porém, junto com os compostos nitrogenados e fósforo, o potássio é elemento importante ao se analisar a possibilidade de eutrofização em ambiente lêntico.

\section{Conclusão}

No período em que foi realizado o estudo, em época de estiagem, os parâmetros DBO, OD, coliformes termotolerantes e fósforo não estiveram de acordo com os padrões estabelecidos pela Resolução no 357/2005 do CONAMA (BRASIL, 2005) para corpos hídricos Classe 1 e pela Resolução $n^{\circ}$ 274/2000 (BRASIL, 2000) do mesmo conselho. Portanto, as águas da Lagoa do Josino não podem ser utilizadas para o abastecimento para consumo humano e à recreação de contato primário, tais como natação, esqui aquático e mergulho.

\section{Agradecimentos}

À FAPEMIG e ao UNIFOR-MG pela concessão de bolsas de Iniciação Científica e financiamento desta pesquisa. 


\title{
WATER QUALITY OF JOSINO'S LAGOON, AT FORMIGA - MG
}

\begin{abstract}
Water is the most important natural resource of the Earth, being essential for life, thus, its quality should be preserved. From this, the aim of this paper was to analyze the quality of Josino Lagoon water, located in Formiga - MG, by physical, chemical and microbiological analysis. To do this, water samples were collected in different parts of the Josino Lagoon, which have different forms of use and occupation in the surrounding area. The following water quality parameters were analyzed, from August to October 2015: pH, electrical conductivity, dissolved oxygen, turbidity, nitrate, nitrite, ammonia, total nitrogen, potassium, phosphorus, iron II, iron III, biochemical oxygen demand (BOD), total solids, total dissolved solids, sedimentable solids, fecal and total coliforms, with five replications. The results obtained for BOD, total phosphorus, fecal coliforms do not agree with the recommendations in Resolution 357/2005 of CONAMA for Class 1 Water Bodies and Resolution 274/2000, of the same Council.
\end{abstract}

Keywords: Surface water contamination. Balneability. Water resources management.

\section{Referências}

AMERICAN PUBLIC HEALTH ASSOCIATION (APHA); AMERICAN WATER WORKS ASSOCIATION (AWWA); WORLD ECONOMIC FORUM (WEF). Standard methods for examination of water and wastewater. 19. ed. Washington: American Public Health Association, 1995. 1193p.

BERNADO, L.; PAZ, L. P. S. Seleção de tecnologias de tratamento de água. São Carlos: LDiBe, 2008. v. 1, p. 25-30.

BRASIL. Ministério do Meio Ambiente. Conselho Nacional do Meio Ambiente. Resolução n 274, de 29 de novembro de 2000. Diário Oficial [da] República Federativa do Brasil, Brasília (DF), 25 jan. 2001. Seção 1, p. 70-71. Disponível em: <http://pesquisa.in.gov.br/imprensa/jsp/visualiza/index. jsp?data $=25 / 01 / 2001 \&$ jornal $=1 \&$ pagina $=170 \&$ totalArquivos $=180>$. Acesso em: 10 maio 2016 .

BRASIL. Ministério do Meio Ambiente. Conselho Nacional do Meio Ambiente. Resolução n 357, de 17 de março de 2005. Dispõe sobre a classificação dos corpos de água e diretrizes ambientais para seu enquadramento, bem como estabelece as condições e padrões de lançamento de efluentes, e dá outras providências. Diário Oficial [da] República Federativa do Brasil, Brasília (DF), 18 mar. 2005. Seção 1, p. 58-63. Disponível em: <http://www.aslaa.com.br/wp-content/uploads/2014/08/aslaa. com_.br_legislacoes_CONAMA-n-357-2005.pdf>. Acesso: 10 maio 2016.

DAMASCENO, L. M. O. Avaliação e monitoramento da qualidade da água do Rio Poti na região de Teresina, PI. Monografia (Graduação em Tecnologia em Meio Ambiente) - Centro Federal de Educação Tecnológica do Piauí, Teresina, 2005.

FRANCO, R. A. M.; HERNANDEZ, F. B. T. Qualidade de água na microbacia do Coqueiro, noroeste do Estado de São Paulo. Water Resources and Irrigation Management, v. 1, n. 1, p. 61-69, 2012. Disponível em: <https://www2.ufrb.edu.br/wrim/wrim-v-1-n-1-2012>. Acesso em: 5 maio 2016. 
FRIES, J.; GETROST, H. Organic reagents for trace analysis. Darmstadt: Merck, 1977. 236p.

JERÔNIMO, C. E. M.; SOUZA, F. R. S. Determinação do índice de qualidade da água da Lagoa de Extremoz - RN: série temporal e correlação a índices pluviométricos. Revista Eletrônica em Gestão, Educação e Tecnologia Ambiental, Santa Maria, v. 10, n. 10, p. 2219-2232, jan./abr. 2013. Disponível em: <https://periodicos.ufsm.br/reget/article/view/7888/pdf>. Acesso em: 7 maio 2016.

LONGO JÚNIOR, M. S.; MANZIONE, R. L.; FERREIRA, J. J. Qualidade da água na Lagoa Furninha, município de Ourinhos/SP. In: SIMPÓSIO BRASILEIRO DE RECURSOS HÍDRICOS, 19., 2011, Maceió. Anais... Maceió: Associação Brasileira de Recursos Hídricos, 2011. Disponível em: <https:// www.abrh.org.br/SGCv3/index.php?PUB $=3 \& I D=81 \& S U M A R I O=2473 \& S T=$ qualidade_da_agua_ na_lagoa_do_corrego_furninha_municipio_de_ourinhos_sp > . Acesso em: $1^{\circ}$ maio 2016.

LEMOS, M.; FERREIRA NETO, M.; DIAS, N. S. Sazonalidade e variabilidade espacial da qualidade da água na Lagoa do Apodi, RN. Revista Brasileira de Engenharia Agrícola e Ambiental, Campina Grande, v. 14, n. 2, p. 155-164, 2010. Disponível em: <http://www.scielo.br/pdf/rbeaa/v14n2/ v14n02a06.pdf>. Acesso em: 30 abr. 2016.

MERCK. The testing of water. 9. ed. Darmstadt: Merck, 1972. 224p.

PAGANINI, W. S. Disposição de esgotos no solo: escoamento à superfície. São Paulo: AESABESP, 1997. p.115-116.

SETTI, A. A.; LIMA, J. E. F. W.; CHAVES, A. G. M.; PEREIRA, I. C. Introdução ao gerenciamento de recursos hídricos. 2. ed. Brasília: ANEEL, 2001. 225p. Disponível em: < http://www.comitepcj. sp.gov.br/download/livro_Introd-Gerenc-Rec-Hidr.pdf>. Acesso em:10 maio 2016.

TUCCI, C. E. M. Água no meio Urbano. In: BRAGA, B.; TUNDISI, J. G.; TUNDISI, T. M.; CIMINELLI, V. S. T. (orgs.). Águas doces no Brasil: capital ecológico, uso e conservação. 4. ed. São Paulo: Escrituras, 2015. cap.12, p. 391-424.

VIANA, L. G.; DIAS, D. F. S.; OLIVEIRA, V. P. S. de; OLIVEIRA, M. M. de. Qualidade das águas da Lagoa do Taí, em São João da Barra (RJ). Boletim do Observatório Ambiental Alberto Ribeiro Lamego, Campos dos Goytacazes, v. 7, n. 1, p. 139-151, 2013. Disponível em: <http://www.essentiaeditora. iff.edu.br/index.php/boletim/article/view/2177-4560.20130010>. Acesso em: 8 maio 2016.

VON SPERLING, M. Noções de qualidade das águas. In: Introdução à qualidade das águas e ao tratamento de esgotos. 3. ed. Belo Horizonte: DESA - UFMG, 2005. cap. 1, p. 15-52.

XAVIER, C. F. Avaliação da influência do uso e ocupação do solo e características geomorfológicas sobre a qualidade das águas de dois reservatórios da região metropolitana de Curitiba - Paraná. 2005. 167p. Dissertação (Mestrado em Ciências do Solo) - Universidade Federal do Paraná, Curitiba, 2005.

Histórico editorial:

Submetido em: 15/05/2016

Aceito em: 23/06/2016 
Como citar:

ABNT

CORDEIRO NETO, J.; THEBALDI, M. S.; VILELA, N. M. S.; SILVA, A. V.; MARTINS, I. P. Qualidade da água da Lagoa do Josino, em Formiga (MG). Revista Agrogeoambiental, Pouso Alegre, v. 9, n. 2, p. 95-107, abr./ jun. 2017. Doi: http://dx.doi.org/10.18406/2316-1817v9n22017998

APA

CORDEIRO NETO, J., THEBALDI, M. S., VILELA, N. M. S., SILVA, A. V. \& MARTINS, I. P. (2017). Qualidade da água da Lagoa do Josino, em Formiga (MG). Revista Agrogeoambiental, Pouso Alegre, 9 (2), 95-107. Doi: http://dx.doi.org/10.18406/2316-1817v9n22017998

$\underline{\mathrm{ISO}}$

CORDEIRO NETO, J.; THEBALDI, M. S.; VILELA, N. M. S.; SILVA, A. V. e MARTINS, I. P. Qualidade da água da Lagoa do Josino, em Formiga (MG). Revista Agrogeoambiental, 2017, vol. 9, n. 2, pp. 95-107. Eissn 2316-1817. Doi: http://dx.doi.org/10.18406/2316-1817v9n22017998

\section{VANCOUVER}

Cordeiro Neto J, Thebaldi MS, Vilela NMS, Silva AV, Martins IP. Qualidade da água da Lagoa do Josino, em Formiga (MG). Rev agrogeoambiental. 2017 abr/jun; 9(2): 95-107. Doi: http://dx.doi.org/10.18406/2316$1817 \mathrm{v} 9 \mathrm{n} 22017998$ 